\title{
Donatella Nebbiai, Le discours des livres, Bibliothèques et manuscrits en Europe $I X^{\mathrm{e}}-\mathrm{XV}^{\mathrm{e}}$ siècle
}

\section{Martina Crosio}

\section{(2) OpenEdition}

\section{Journals}

\section{Édition électronique}

URL : http://journals.openedition.org/studifrancesi/4280

DOI : $10.4000 /$ studifrancesi.4280

ISSN : 2421-5856

\section{Éditeur}

Rosenberg \& Sellier

\section{Édition imprimée}

Date de publication : 1 septembre 2016

Pagination : 297-298

ISSN : 0039-2944

\section{Référence électronique}

Martina Crosio, "Donatella Nebbiai, Le discours des livres, Bibliothèques et manuscrits en Europe $1 x^{\mathrm{e}}$ $x v^{2}$ siècle », Studi Francesi [En ligne], 179 (LX | II) | 2016, mis en ligne le 01 septembre 2016, consulté le 18 septembre 2020. URL : http://journals.openedition.org/studifrancesi/4280 ; DOI : https://doi.org/ 10.4000/studifrancesi.4280

Ce document a été généré automatiquement le 18 septembre 2020.

\section{(c)}

Studi Francesi è distribuita con Licenza Creative Commons Attribuzione - Non commerciale - Non opere derivate 4.0 Internazionale. 


\title{
Donatella Nebbiai, Le discours des livres, Bibliothèques et manuscrits en Europe $I X^{\mathrm{e}}-X V^{\mathrm{e}}$ siècle
}

\author{
Martina Crosio
}

\section{RÉFÉRENCE}

DONATELLA NEBBIAI, Le discours des livres, Bibliothèques et manuscrits en Europe I $\mathrm{X}^{\mathrm{e}}$-XV $\mathrm{X}^{\mathrm{e}}$ siècle, Presses Universitaires de Rennes, 2013, Collection «Histoire», 311 pp.

1 Dans une étude illustrée par de nombreux exemples tirés d'une vaste gamme de sources, Donatella Nebbiai vise à offrir une présentation d'ensemble de l'état des livres et des bibliothèques au Moyen Âge: étude ambitieuse, car il s'agissait de reconstituer sept siècles d'histoire ( $\mathrm{du} \mathrm{IX}^{\mathrm{e}}$ au $\mathrm{XV}^{\mathrm{e}}$ siècle) en retraçant l'évolution de la notion de livre et du rôle des bibliothèques dans l'Europe occidentale, notamment en France et en Italie.

2 Le livre, divisé en quatre parties et enrichi d'une vingtaine de reproductions de manuscrits en noir et blanc, suit un parcours chronologique qui débute avec la Renaissance carolingienne (1ère partie) et, en traversant les siècles d'or de la scolastique (3ème partie), s'achève avec l'essor de l'humanisme et l'invention de l'imprimerie (4ème partie). Une section à part est consacrée aux rapports entre les archives et les bibliothèques et à l'essor de la pratique documentaire au sein des communautés religieuses (2ème partie). Le volume est enfin complété par un répertoire chronologique des listes et des inventaires de livres cités, une riche bibliographie et un index des noms (pp. 247-306).

3 À la fois conteneur de textes et objet manufacturé, le manuscrit a beaucoup changé au fil du temps, tant dans son contenu que dans ses conditions de circulation et d'utilisation. 
4 Le manuscrit carolingien, objet précieux doté d'une forte charge symbolique, commence à s'affirmer comme outil de communication à l'intérieur d'un cercle de savants bibliophiles appartenant au milieu de la cour. Grâce aux annotations que ceuxci ont ajoutées dans les marges, nous pouvons reconstruire leurs méthodes de travail: ils disposaient en effet d'un arsenal de signes diacritiques par lesquels ils notaient des corrections, des variantes, des réflexions et des citations bibliques. À cette époque la lecture et l'écriture sont de fait l'apanage du clergé, qui alimente une production manuscrite composée essentiellement de livres de culte.

5 À la fin du XII siècle, avec la floraison de la culture scolastique, un nouveau type de livre s'impose. Avant tout support d'apprentissage et outil didactique, le livre scolastique présente une série de dispositifs à l'usage des professeurs et des étudiants qui aident à la lecture et à la mémorisation: mise en page sur deux colonnes, rubriques, tables des matières et larges espaces laissés vides pour accueillir des ajouts et des commentaires.

6 Si la plupart des copistes sont désormais des laïcs, les principaux promoteurs et commanditaires des livres demeurent les clercs et les ecclésiastiques. Dans les villes universitaires se répand alors une façon de copier les livres d'étude plus efficace et organisée: le célèbre système dit de la pecia. Sur le plan du contenu, le livre accueille toute une série de nouveaux textes liés à la culture scolastique et aux exigences de la prédication des ordres mendiants: recueils d'extraits, glossaires, commentaires, sommes et concordances bibliques.

7 À la fin du Moyen Âge on enregistre une nouvelle augmentation du nombre des lecteurs et une plus large diffusion des livres dans les couches sociales moyennes du milieu urbain. Dans les villes, la pratique de l'écrit se répand chez les professionnels qui disposent de collections privées, parfois composées de plusieurs volumes. Avec sa haute conception de l'écriture, Pétrarque exerce alors une importante influence intellectuelle dans le domaine des pratiques culturelles de l'humanisme français. C'est à cette époque qu'en visitant les bibliothèques monastiques, les savants humanistes redécouvrent les œuvres de l'Antiquité classique que l'on croyait perdues. Nous sommes toujours les débiteurs envers ces érudits d'une pratique de travail sur les textes, la méthode philologique, que nous adoptons, avec des corrections, aujourd'hui encore.

Il faut toutefois ramener le manuscrit dans son contexte d'origine et d'utilisation pour en saisir sa valeur historique: celui-ci ne dégage en effet tout son sens que s'il n'est inscrit dans la collection dont il a fait partie. La notion de bibliothèque a inclus, tout au long $\mathrm{du}$ Moyen Âge, des réalités très différentes. À la fois centres d'études et instruments de la politique culturelle de l'empereur, les premières bibliothèques carolingiennes se constituent au sein des institutions religieuses pour répondre aux besoins du culte. Les rares collections laïques, dont il est presque impossible d'évaluer la composition, appartiennent aux grandes personnalités liées à la cour.

9 Initialement les bibliothèques ne sont ni physiquement ni conceptuellement séparées des archives: leur gestion est souvent confiée à une seule et même personne; néanmoins, au fil du temps ces deux entités se diversifient, chacune s'affirmant avec son propre rôle spécifique.

10 Les bibliothécaires sont chargés de dresser ou de mettre à jour les inventaires, d'organiser les prêts et de veiller au bon usage des livres dans le cadre de la liturgie. $\mathrm{Ne}$ pouvant pas disposer de biens ou de propriétés, dès le XIII ${ }^{\mathrm{e}}$ siècle les ordres mendiants 
organisent et réglementent le prêt des livres: plusieurs dispositifs, tels que les étiquettes et les cotes, sont mis au point pour favoriser la consultation et pour rationaliser la gestion des collections. Témoignages des pratiques bibliothéconomiques de l'époque, les cotes se répandent et deviennent de plus en plus complexes et performantes à mesure que les collections s'amplifient. Les catalogues, qui présentent généralement des classements thématiques par matières, se perfectionnent et donnent parfois même des indications sur la localisation des volumes.

11 Depuis la fondation de la Sorbonne, le nouveau modèle d'organisation bipartite de la bibliothèque - avec d'une part la libraria communis, à savoir le fonds officiel accessible à la consultation sur place, et de l'autre la collection destinée au prêt - se généralise.

L'exigence de disposer de textes plus corrects et de meilleure qualité conduit, dans les abbayes et dans les couvents, à des campagnes de copie et à des commandes de nouveaux manuscrits: c'est à l'époque de la scolastique que les germes d'un véritable esprit philologique apparaissent et qu'une attention nouvelle à l'exactitude et à l'intégrité des œuvres se développe.

13 Églises et couvents ne sont pas seulement les destinataires privilégiés des legs des ecclésiastiques, mais aussi les bénéficiaires des dons de propriétaires laïcs qui lèguent leurs livres à ces institutions en témoignage de dévotion. De cette façon le flux des livres qui transite des collections privées aux collections des institutions alimente et modifie le contenu des bibliothèques religieuses.

14 À la fin du Moyen Âge la diffusion des pratiques de lecture dans de nouveaux milieux sociaux conduit à la création des premières bibliothèques publiques. À Paris la bibliothèque de Charles $\mathrm{V}$, renforçant le pouvoir du souverain, relève l'enjeu culturel de l'humanisme et devient un modèle de référence pour les collections princières dans toute l'Europe. La bibliothèque d'État, qui naît en Italie au cours du $\mathrm{xv}^{\mathrm{e}}$ siècle, se caractérise à la fois par ses contenus et par son fonctionnement. Conformément aux principes de la culture humaniste, la bibliothèque publique offre aux lecteurs des textes de haute qualité et combine les savoirs de l'Antiquité classique avec les valeurs du Christianisme.

15 Le volume de Donatella Nebbiai constitue une contribution scientifique très bien documentée qui met en lumière l'histoire du livre surtout du point de vue de l'utilisation et des pratiques de lecture sur une longue durée. Certes, on pourrait lui reprocher d'avoir laissé de côté des aspects tels que le fonctionnement des scriptoria ou les modes de production des manuscrits; mais on reconnaîtra que, grâce à la clarté du plan et de l'exposé, et à l'adoption d'une structure chronologique, ce livre offrira un efficace support d'apprentissage dans les enseignements universitaires de littérature médiévale, et en même temps permettra à un public de non-spécialistes curieux de découvrir l'univers du livre médiéval. 